\title{
Correlation and Path Analysis in Commercial Tenera Oil Palms Collected from Southern Thailand
}

Key words: Correlation, Oil palm, Path analysis, Tenera.

\section{INTRODUCTION}

Oil palm (Elaeis guineensis Jacq.) is native to the tropical rainforests of West and Central Africa and was brought to Southeast Asia in the early nineteenth century for commercial cultivation (Giacomin, 2018). Oil palm yields more compare oil than other oil crops. Palm oil is extracted from mesocarp and kernel. It is used for several purposes such as food ingredient, cosmetics and biodiesels. (Corley and Tinker, 2003). The tenera oil palm, the $F_{1}$ hybrid between Dura (maternal) type and Pisifera (paternal) type, is wildly planted for commercial purposes throughout Southern Thailand. The tenera has a thin endocarp (shell) $\left(S h^{+} S h^{-}\right)$, thick mesocarp and fiber ring surrounding the endocarp (Soonsuwon et al. 2020). In oil palm breeding programs, plant breeders consider such things as bunch yield improvement, oil yield improvement, drought tolerance improvement, disease resistance improvement, etc. (Kumar et al. 2018). The correlation is a statistical technique used in oil palm breeding to identify the relationships among the quantitative variables of plant characteristics (Karadavut and Sozen, 2017). The correlation coefficient ranges between -1 and +1 . When positive correlation $(r>0)$ indicates change in the same direction, both variables increase. When negative correlation $(r<0)$ means that two variables move in opposite directions; one variable decreases as the other increases. When $r=0$, there is no association between the two variables (Gagné 2014; Franzese and Iuliano, 2019). The path analysis is an extension of the multiple regression; it investigates patterns of how independent variables produce direct and indirect effects on dependent variables (Lekshmanan and Vahab, 2018). The results of path analysis
Agricultural Innovation and Management Division, Faculty of Natural Resources, Prince of Songkla University, Hatyai, Songkhla, 90110, Thailand.

Corresponding Author: Thanet Khomphet, School of Agricultural Technology and Food Industry, Walailak University, Thasala, Nakhon si Thammarat, 80160, Thailand.

Email: thanet.kh@wu.ac.th

How to cite this article: Popet, P., Eksomtramage, T., Anothai, J. and Khomphet, T. (2021). Correlation and Path Analysis in Commercial Tenera Oil Palms Collected from Southern Thailand. Indian Journal of Agricultural Research. DOI: 10.18805/IJARe.A-631.

Submitted: 13-03-2021 Accepted: 11-11-2021 Online: 22-12-2021

consist of direct effects from an independent variable on a dependent variable and indirect effects from an independent variable on a dependent variable through another independent variable. Path analysis assists in identification of characteristics that are useful as selection criteria for yield improvement (Olkin and Sampson, 2001; Osman et al. 2012). This study evaluated the phenotypic correlations and the direct and indirect effects among bunch yields and vegetative characteristics in commercial tenera oil palms. The results from this study might be useful for further breeding programs of oil palms in Thailand.

\section{MATERIALS AND METHODS}

The six progenies of commercial tenera oil palms collected from Southern Thailand were planted in August 2015 at Oil Palm Collection Center, The Chaipattana Foundation, Trang 
Province $\left(7^{\circ} 39^{\prime} 45.1^{\prime \prime} \mathrm{N} 99^{\circ} 36^{\prime} 03.3^{\prime \prime} \mathrm{E}\right)$. They were planted at $9 \times 9 \times 9 \mathrm{~m}$ in triangular formation. For data collection, the 15 oil palm trees of each commercial tenera oil palm were randomly selected from the 4-year-old oil palm plantation. The bunch yields [fresh fruit bunch (FFB), bunch number (BN), average bunch weight (ABW) and oil yield $(\mathrm{OY})$ ] and vegetative characteristics [leaf area (LA), leaf dry weight (LDW) and rachis length $(R L)$ ] were collected from each selected oil palm tree. The oil yield was analyzed by the method reported by Corley (2018) and the leaf area and leaf dry weight were estimated by the method reported by Eksomtramage (2015). The study was conducted between January 2019 and June 2020. The data was statistically analyzed in phenotypic correlation coefficient $\left(r_{p}\right)$ with the method reported byAl-jibouri et al. (1958) and Ly et al. (2018) as follows:

$$
\text { Phenotypic correlation }=\frac{\operatorname{Cov}(p h) X Y}{\sqrt{\sigma^{2}(p h) X^{*} \sigma^{2}(p h) Y}}
$$

Where:

$\operatorname{Cov}(\mathrm{ph}) \mathrm{XY}=$ Phenotypic covariance between the variable $X$ and $Y$.

$\sigma^{2}(\mathrm{ph}) \mathrm{Y}=$ Phenotypic variance of the variable $\mathrm{Y}$.

$\sigma^{2}(\mathrm{ph}) \mathrm{X}=$ Phenotypic variance of the variable $X$.

The path analysis was calculated by the method reported by Krualee et al. (2013) and Eksomtramage (2015) as follows:

Where

$$
\begin{aligned}
& b_{1}^{\prime}=\frac{\sigma x_{1}}{\sigma y} \\
& b_{2}^{\prime}=\frac{\sigma x_{2}}{\sigma y}
\end{aligned}
$$

$b_{1}, b_{2}^{\prime}=$ Path coefficient values.

$r_{12}, r_{13}=$ Correlation coefficient values between $X_{1}$ and $X_{2}, X_{1}$ and $\mathrm{X}_{3}$.

The path coefficient values can be substituted in the simultaneous equation $r_{1 y}=b^{\prime}{ }_{1}^{*} r_{11}+b^{\prime}{ }_{2}^{*} r_{12}+b^{\prime}{ }_{3}^{*} r_{13}+$

\section{RESULTS AND DISCUSSION}

Phenotypic correlation among bunch yields and vegetative characteristics

The phenotypic correlations among bunch yields and vegetative characteristics in commercial tenera oil palms are illustrated in Table 1. All characteristics were positively correlated with each other characteristics, except for BN which was negatively correlated with other characteristics. OY was positively and significantly correlated with FFB, ABW and $R L\left(r_{p}=0.90^{* *}, 0.50^{*}\right.$ and $0.53^{*}$, respectively). FFB was positively and significantly correlated with $B N$ and $R L\left(r_{p}=\right.$ $0.58^{*}$ and $47^{*}$, respectively), while $B N$ was negatively and significantly correlated with ABW $\left(r_{p}=-0.57^{*}\right)$. ABW was positively and significantly correlated with $L A$ and $R L\left(r_{p}=\right.$ $0.63^{* *}$ and $0.56^{*}$, respectively). For the vegetative characteristics, LA was positively and significantly correlated with LDW and RL $\left(r_{p}=0.65^{\star *}\right.$ and $0.76^{* *}$, respectively) and LDW was positively and significantly correlated with ABW $\left(r_{p}=0.55^{*}\right)$. The results from this study are similar to the previous reports from Pathpo (2007); Eksomtramage and Eksomtramage (2010); Krualee et al. (2013); Rafll et al. (2013); Songrit (2014); Bueraheng (2017) who reported that OY was positively and significantly correlated with FFB and $A B W$. It indicates that the increase of $F F B$ and $B N$ will increase OY. Positive and significant correlations were also found between FFB and $B N$, indicating that an increase of $B N$ will increase FFB. $B N$ was negatively correlated with $A B W$, indicating that the increase of $B N$ will result in the decrease of $A B W$.

\section{Path analysis among bunch yields and vegetative characteristics}

The results of path analysis among bunch yields and vegetative characteristics on fresh fruit bunch in commercial tenera oil palms are illustrated in Table 2. FFB was positively and significantly correlated with $B N$ and $R L\left(r_{p}=0.58^{* *}\right.$ and $0.47^{*}$, respectively). In addition, BN (1.11) and ABW (0.93) had strongly positive direct effects on FFB, while ABW had positive indirect effects on FFB through BN (-0.53), LA (0.59), LDW (0.37) and RL (0.52). The results are similar to results from Pathpo (2007); Eksomtramage (2015); Bueraheng (2017) who reported that $B N$ and $A B W$ had positive indirect effects on FFB. The results of path analysis among bunch yields and vegetative characteristics on oil yield in commercial tenera oil palms are illustrated in Table 3. OY was positively and significantly correlated with $F F B, A B W$ and $\mathrm{RL}\left(\mathrm{r}_{\mathrm{p}}=0.90^{* *}, 0.50^{*}\right.$ and $0.53^{*}$, respectively). FFB had the highest positive direct (2.08) and/or indirect effects

\begin{tabular}{|c|c|c|c|c|c|c|c|}
\hline Characteristics & OY & FFB & $\mathrm{BN}$ & ABW & LA & LDW & $\mathrm{RL}$ \\
\hline OY & - & 0.90 ** & 0.31 & $0.50^{*}$ & 0.36 & 0.16 & $0.53^{*}$ \\
\hline FFB & & - & $0.58^{*}$ & 0.33 & 0.29 & 0.00 & $0.47^{*}$ \\
\hline BN & & & - & $-0.57^{\star}$ & -0.31 & -0.37 & -0.10 \\
\hline ABW & & & & - & $0.63^{* *}$ & 0.40 & $0.56^{*}$ \\
\hline LA & & & & & - & $0.65^{* *}$ & $0.76^{* *}$ \\
\hline LDW & & & & & & - & $0.55^{*}$ \\
\hline$R L$ & & & & & & & - \\
\hline
\end{tabular}
(through BN (1.20)) on OY. In contrast, BN had negative

Table 1: Phenotypic correlation among bunch yields and vegetative characteristics in commercial tenera oil palms.

* ** Significantly different at $\mathrm{P}<0.05$ and $\mathrm{p}<0.01$, respectively. $\mathrm{OY}=$ Oil yield (kg/palm/year), FFB= Fresh fruit bunch $(\mathrm{kg} / \mathrm{palm} / \mathrm{year}), \mathrm{BN}=\mathrm{Bunch}$ number (no./year), ABW= Average bunch weight (kg/bunch), LA= Leaf area $\left(\mathrm{m}^{2}\right), \mathrm{LDW}=$ Leaf dry weight $(\mathrm{kg}), \mathrm{RL}=\mathrm{Rachis}$ length $(\mathrm{cm})$. 
Correlation and Path Analysis in Commercial Tenera Oil Palms Collected from Southern Thailand

Table 2: Path analysis among bunch yields and vegetative characteristics on fresh fruit bunch in commercial tenera oil palms.

\begin{tabular}{|c|c|c|c|c|c|c|c|}
\hline \multirow{2}{*}{ Characteristics } & \multirow{2}{*}{ Correlation } & \multirow{2}{*}{ Direct effect } & \multicolumn{5}{|c|}{ Indirect effect } \\
\hline & & & $\mathrm{BN}$ & ABW & LA & LDW & $\mathrm{RL}$ \\
\hline $\mathrm{BN}$ & $0.58^{*}$ & 1.11 & - & -0.53 & 0.00 & -0.01 & 0.00 \\
\hline ABW & 0.33 & 0.93 & -0.63 & - & 0.00 & 0.01 & 0.03 \\
\hline LA & 0.29 & 0.00 & -0.35 & 0.59 & - & 0.01 & 0.04 \\
\hline LDW & 0.00 & 0.01 & -0.41 & 0.37 & 0.00 & - & 0.03 \\
\hline $\mathrm{RL}$ & $0.47^{*}$ & 0.06 & -0.11 & 0.52 & 0.00 & 0.01 & - \\
\hline
\end{tabular}

*, ** Significantly different at $\mathrm{P}<0.05$ and $\mathrm{p}<0.01$, respectively. OY $=$ Oil yield $(\mathrm{kg} /$ palm/year), $\mathrm{FFB}=\mathrm{Fresh}$ fruit bunch $(\mathrm{kg} / \mathrm{palm} / \mathrm{year})$, $\mathrm{BN}=$ Bunch number (no./year), $\mathrm{ABW}=$ Average bunch weight $(\mathrm{kg} / \mathrm{bunch}), \mathrm{LA}=$ Leaf area $\left(\mathrm{m}^{2}\right), \mathrm{LDW}=$ Leaf dry weight $(\mathrm{kg}), \mathrm{RL}=\mathrm{Rachis}$ length $(\mathrm{cm})$.

Table 3: Path analysis among bunch yields and vegetative characteristics on oil yield in commercial tenera oil palms.

\begin{tabular}{lccccccrc}
\hline \multirow{2}{*}{ Characteristics } & \multirow{2}{*}{ Correlation } & \multirow{2}{*}{ Direct effect } & \multicolumn{5}{c}{ Indirect effect } \\
\cline { 4 - 8 } & & & FFB & BN & ABW & LA & LDW & RL \\
\hline FFB & $0.90^{* *}$ & 2.08 & - & -0.82 & -0.32 & -0.04 & 0.00 & 0.00 \\
BN & 0.31 & -1.43 & 1.20 & - & 0.54 & 0.05 & -0.04 & 0.00 \\
ABW & $0.50^{*}$ & -0.95 & 0.70 & 0.81 & - & -0.09 & 0.04 & 0.00 \\
LA & 0.36 & -0.15 & 0.60 & 0.45 & -0.60 & - & 0.06 & 0.00 \\
LDW & 0.16 & 0.10 & 0.01 & 0.53 & -0.38 & -0.10 & - & 0.00 \\
RL & $0.53^{*}$ & 0.00 & 0.98 & 0.15 & -0.54 & -0.11 & 0.05 & - \\
\hline
\end{tabular}

*, ** Significant difference at $\mathrm{P}<0.05$ and $\mathrm{p}<0.01$, respectively. OY= Oil yield (kg/palm/year), $\mathrm{FFB}=$ Fresh fruit bunch (kg/palm/year), BN= Bunch number (no./year), ABW= Average bunch weight (kg/bunch), LA= Leaf area $\left(\mathrm{m}^{2}\right), \mathrm{LDW}=$ Leaf dry weight $(\mathrm{kg}), \mathrm{RL}=\mathrm{Rachis}$ length $(\mathrm{cm})$.

direct effects $(-1.43)$ and negative and positive indirect effects on OY through FFB (-0.82) and ABW (0.81). ABW had negative direct $(-0.95)$ and indirect effects on OY though LA $(-0.60)$ and $\mathrm{RL}$ (-0.54). According to Pathpo (2007); Eksomtramage (2015), FFB had positive indirect effects on OY.

\section{CONCLUSION}

Oil yield was positively and significantly correlated with fresh fruit bunch, average bunch weight and rachis length. Fresh fruit bunch had the highest positive direct and indirect effects on oil yield. Fresh fruit bunch was positively and significantly correlated with bunch number and rachis length. The path analysis indicates that bunch number and average bunch weight had strongly positive direct effects on fresh fruit bunch, although the average bunch weight was not significantly correlated with fresh fruit bunch. Therefore, bunch number and fresh fruit bunch are the most important variables which might be used in oil palm breeding programs. Both variables were positively and significantly correlated with oil yield and had strong direct and indirect effects on the yield.

\section{ACKNOWLEDGEMENT}

We are thankful to Oil Palm Collection Center, The Chaipattana Foundation for supporting plant materials.

\section{REFERENCES}

Al-Jibouri, H.A., Kitter, P.A. and Robinson, H.F. (1958). Genotypic and environmental variations and covariances in an upland cotton cross of interspecific origin. Agronomy Journal. 50: 533-536.
Bueraheng, N., Promma, S. and Eksomtramage, T. (2017). Biplot analysis of agronomic and yield trait relations in tenera oil palm (Elaeis guineensis Jacq.). Songklanakarin Journal of Science and Technology. 39: 709-714.

Corley, R.H.V. (2018). Studies of bunch analysis 1 - variation within and between palms. Journal of Oil Palm Research. 30: 196-205.

Corley, R.H.V. and Tinker, P.B. (2003). The Oil Palm. $4^{\text {th }}$ Edn. Blackwell Publishing Company, Oxford. pp. 562.

Eksomtramage, T. (2015). Oil Palm Breeding. $2^{\text {nd }}$ Edn. OS. Printing House, Bangkok. pp. 463.

Eksomtramage, W. and Eksomtramage, T. (2010). Heritability and correlations of agronomic characters in tenera oil palm hybrid. Journal of Agriculture. 26: 231-239.

Franzese, M. and Iuliano, A. (2019). Correlation Analysis. In: Encyclopedia of Bioinformatics and Computational Biology. Cambridge, Elsevier.

Gagné, F. (2014). Descriptive Statistics and Analysis in Biochemical Ecotoxicology. In: Biochemical Ecotoxicology. Canada, Academic Press.

Giacomin, V. (2018). The transformation of the global palm oil cluster: Dynamics of cluster competition between Africa and Southeast Asia (c.1900-1970). Journal of Global History. 13: 374-398.

Karadavut, U. and Sozen, O. (2017). Pearson and canonical correlations between the root properties and some yield components of chickpea (Cicer Arietinum L.). Legume Research. 40: 890-895.

Krualee, S., Sdoodee, S., Eksomtramage, T. and Sereeprasert, V. (2013). Correlation and path analysis of palm oil yield components in oil palm (Elaeis guineensis Jacq.). Kasetsart Journal. 47: 528-533. 
Kurmar, P.N., Babu, B.K., Mathur, R.K. and Ramajayam, D. (2018). Genetic Engineering of Oil Palm. In: Genetic Engineering of Horticultural Crops. Bhubaneswar, Academic Press.

Lekshmanan, D.K. and Vahab M.A. (2018). Correlation and path coefficient analysis of yield and its component characters among different accessions of cluster bean [Cyamopsis tetragonoloba (L.) Taub.]. Legume Research. 41: 53-56.

Ly, A., Marsman, M. and Wagenmakers, E. (2018). Analytic posteriors for Pearson's correlation coefficient. Statistica Neerlandica. 72: 4-13.

Olkin, I. and Sampson, A.R. (2001). Multivariate Analysis: Overview. In: International Encyclopedia of the Social and Behavioral Sciences. Pergamon, Elsevier Ltd.

Osman, K.A., Mustafa, A.M., Ali, F., Yonglain, Z. and Fazhan, Q. (2012). Genetic variability for yield and related attributes of upland rice genotypes in semi-arid zone (Sudan). African Journal of Agricultural Research. 7: 4613-4619.
Pathpo, P. (2007). Genetic Variance components of growth characters and yield in oil palm (Elaeis guineensis Jacq.). M.Sc. Thesis. Prince of Songkla University, Songkla.

Rafll, M.Y., Isa, Z.A., Kushairi, A., Saleh, G.B. and Latif, M.A. (2013). Variation in yield components and vegetative traits in Malaysian oil palm (Elaeis guineensis jacq.) dura $\times$ pisifera hybrid under various planting densities. Industrial Crops and Products. 46: 147-157.

Songrit, N. (2014). Heritabilities and correlations of vegetative growth and yield component characters in tenera oil palm. M.Sc. Thesis. Prince of Songkla University, Songkla.

Soonsuwon, W., Eksomtramage, T., Nakkanong, K., Songsri, N. and Kaewsrisom, H. (2020). Identifying $F_{2}$ oil palm (Elaeis guineensis Jacq.) trees for their dura, pisifera and tenera types using fruit morphology and SSR markers. Indian Journal of Agricultural Research. 54: 399-403. 